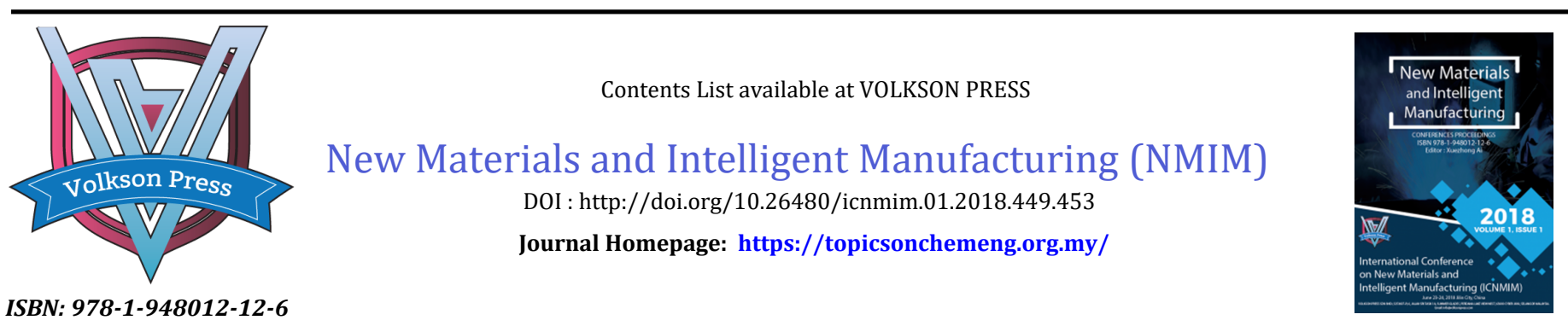

\title{
COMPETITION ANALYSIS FOR SHARED SPECTRUM WITH A PRIORITY QUEUE MODEL
}

\author{
Lijun Zheng, Feng Liu \\ Department of Computer, Jilin Institute of Chemical Technology, ChengDe Street 45\#, JiLin, China.
}

This is an open access article distributed under the Creative Commons Attribution License, which permits unrestricted use, distribution, and reproduction in any medium, provided the original work is properly cited

\section{ARTICLE DETAILS}

\section{Article History:}

Received 26 June 2018 Accepted 2 July 2018

Available online 1 August 2018

\section{ABSTRACT}

Spectrum sharing has been proposed as a way to improve the capacity of wireless network by using limited spectrum more efficiently. This paper provides a scenario where a primary service provider shares one spectrum with secondary service providers and competes for a common customer pool with them. It is by using price competition models to study a scenario where a customer chooses a service provider based on the price of the service and the congestion it generated. Here we assume that the primary service provider has absolute priority over the secondary ones and simulate the resulting congestion by preempting the priority queue. We described how the price games result in equilibrium. Particularly, we find out that, when the service time has a little change, the secondary service provider could be expelled out of the system while the primary service provider must supply a price below its expectations if it feels the threat of new entrants as a monopolist. As the available bandwidth increases, the profit of the primary service provider will decrease to zero gradually.

\section{KEYWORDS}

Priority Queue Model, spectrum sharing, competition, monopoly, Wardrop balance, Nash equilibrium

\section{INTRODUCTION}

Based on a study, to satisfy the future demands of wireless data services, sharing has been proposed as an effective way to unlock additional spectrum [1-5]. Many researches go into the "primary-secondary" approach to spectrum sharing, where secondary users can access a spectrum provided to them as long as they do not interfere with primary users [6-8]. This paper focuses on a "primary and secondary" scenario where a wireless service provider (SP) is the primary spectrum user. This primary SP is sharing with a set of secondary SPs. Here we consider an unauthorized secondary sharing model, this means that any secondary SP can access a given spectrum and do not interfere with the primary SP. According to a research, it can be compared with licensed secondary access, where a single SP has an exclusive secondary use license [9]. Allowing such an unauthorized sharing reduces the barriers for the secondary SP to enter into the market and enables them to provide lowcost services; While the competitions among them could increase social welfare. Lowering the entry threshold also brings extra congestion to the secondary SP and affects the pricing strategy of the primary SP. This paper presents a model for studying such problems.

After this paper continues a series of work to study the competition of spectrum sharing. These work in turn are based on the actual operation and the strain resource competition model studied in the economic literature, including [10-14]. In these models, companies compete for customers by claiming prices. The customers choose SPs based on the combination of their claimed price and the level of the congestion in the company resources. Companies have independent resources, and with spectrum sharing, some resources are shared by SPs. In this paper, an unlicensed spectrum band can be used for all the SPs' band, authorized share is taken into account, whereas unauthorized sharing of a band under the primary-secondary model is supposed in this paper. In this paper, we consider at a more accurate model based on a preemptive priority queue to simulate the congestion costs of the primary and secondary SPs.

The rest of the paper as follows: section 2 describes price competition and congestion models based on priority queues. In section 3 , we analyze the competitive equilibrium and the benefits of spectrum sharing and no spectrum sharing. In the end, we conclude in section 4 .

\section{COMPETITION MODEL}

As in reference, we provide the competitive model of a wireless service market, where SPs declares the price of its services for a common pool of customers. The service quality provided by each SP is simulated with congestion cost. In this paper, we modeled the congestion as the average latency for customers to accept service assuming that customers are served in order by SPs using the entire spectrum in a given area. Each customer then selects a SP based on all SPs' provided services and prices. Specifically, the customer chooses SP for the lowest delivered price (the sum of their declared price and congestion cost).

\subsection{Supply and demand}

Supply: we focus on a wireless service market where there is an existing SP. When there is no spectrum sharing, it is like a monopolist. In the case of spectrum sharing, it declares price $p$, and competes with the $N>2$ secondary SPs who declare price, $\mathrm{P}^{\mathrm{s}}=\left(\mathrm{p}_{1} \mathrm{~s}, \mathrm{p}_{2}^{\mathrm{s}}, \ldots, \mathrm{p}_{\mathrm{N}}{ }^{\mathrm{s}}\right)$ and serve $\mathrm{X}=\left(\mathrm{x}_{1} \mathrm{~s}\right.$, $\mathrm{x}_{2} \mathrm{~s}, \ldots, \mathrm{x}_{\mathrm{N}} \mathrm{s}$ ) customers, respectively.

The service quality of primary SP is given by the congestion cost $\mathrm{g}(\mathrm{x})$, depending only on $\mathrm{x}$, the number of customers (primary users). This describes a scenario where the primary user does not feel any interference from the secondary user. On the other hand, the service of the secondary $\mathrm{SP}$ is reduced compared to the primary SP because of the priority giving to the primary SP and the delay of waiting for the release of the available spectrum. The congestion is given by gs $\left(\mathrm{x}_{1}, \mathrm{x}_{2}\right)$, where $\mathrm{x}_{2}=\sum \mathrm{x}_{\mathrm{i}}^{\mathrm{S}}$ is the total number of secondary users. This indicates that secondary users are not only disturbed by themselves, but also by primary users. Generally, we assume that $\mathrm{g}($.$) and gs(.) are continuous, increasing and convex functions$ with $g(0)=g s(0)=0$ (see Fig. 1 ); the specific features we consider in this paper will be defined in section 2.2 . 


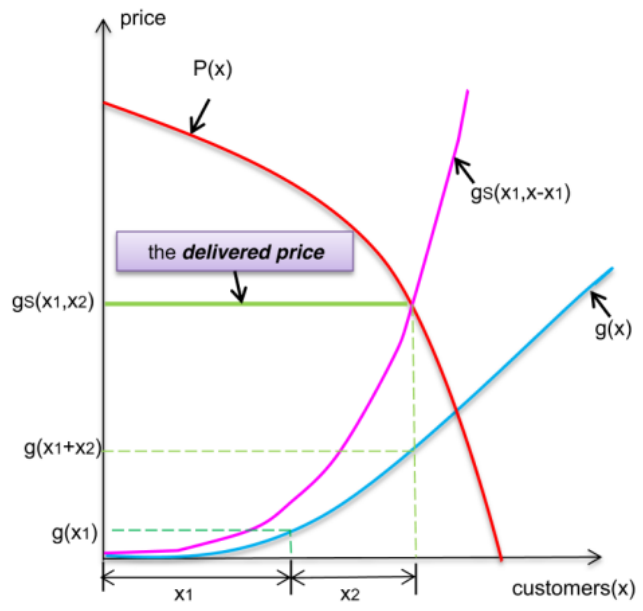

Figure 1: Priority Queue Model for the Pricing Game with Shared Spectrum.

Demand: we assume that there is a small group of customers and the total number of customers is normalized to be 1 . We use an inverse demand function $\mathrm{P}(\mathrm{x})$ to describe the customers' need for service at a given price. This is non-increasing, left-continuous, concave function that represents how much a group of $\mathrm{x}$ customers are willing to pay. Previously, the delivered price is the sum of the price each customer needs to pay and the congestion they experience. Each customer can choose to be a primary or secondary user, and the delivered prices $\mathrm{p}_{1}+\mathrm{g}\left(\mathrm{x}_{1}\right)$, or $\mathrm{p}_{\mathrm{k}}{ }^{\mathrm{s}}+\mathrm{gs}\left(\mathrm{x}_{1}, \mathrm{x}_{2}\right)$, respectively. Otherwise, if a average delivered price is higher than that the customers are willing to pay for, they will not accept the service. Additionally, we assume $\mathrm{P}(\mathrm{x})>0$ for small enough value of $\mathrm{x}$ so that there will always be a price low enough some customers are willing to pay for. Each customer wants to select a SP who provides the lowest delivery price (offering no higher than the price they are willing to pay for). If more than one SP has the same delivered price, the customer will randomly select a $\mathrm{SP}$ with low price. Therefore, with a set of prices (p, $\left.\mathrm{P}^{\mathrm{s}}\right)$, the customers receiving the service will be in a Wardrop balance [15], i.e. :

(1) The delivered prices of all active SPs (i.e., those serving customers) are equal and strictly less than the delivered price of any inactive SP;

(2) If active SPs are serving a total number customer of $x=x_{1}+x_{2}$, then the delivered price of these SPs, $y$ satisfies $y \leq P(x)$ and $y>P(x+\varepsilon)$ for any $\varepsilon>0$.

Note that the second condition specifies that the delivered price any unserviced customer sees is higher than that he is willing to pay for. And note that if $P(x)$ is continuous with $x$, then $y=P(x)$ equivalently.

\subsection{Congestion and Priority Queue}

Previously, we provided a scenario where all customers are served in order, while the primary SP customers have priority over the secondary SP customers. To the congestion of the primary and secondary SPs, we adopte a model based on the average waiting time of the forecast in the M/G/1 system, there are two priorities: priority 1 and priority 2. Priority 1 , for primary SP, with a higher preemptive priority, models for a situation when the primary SP needs to use the spectrum, the secondary SP immediately stops serving. For such a system, the average wait time W1 and W2 for each priority i is [16]:

$$
\text { Level 2: } \mathrm{W}_{2}=\frac{\frac{1}{2}\left(\lambda_{1} \overline{\mathrm{Y}}_{1}^{2}+\lambda_{2} \overline{\mathrm{Y}}_{2}^{2}\right)}{\left(1-\frac{\lambda_{1}}{\mu_{1}}\right)\left(1-\frac{\lambda_{1}}{\mu_{1}}-\frac{\lambda_{2}}{\mu_{2}}\right)}
$$

where $\lambda_{i}, \bar{Y}_{i}=1 / \mu_{i}$, and $\bar{Y}_{i}^{2}$ are the arrival rate of priority $i$ and the first two time points of the service respectively. We use them as the congestion costs for the primary and secondary services.

To simplify the notation, for each of the priority $i$, let's say $a_{i}=\bar{Y}_{i}^{2} / 2$, $b_{i}=\bar{Y}_{i}=1 / \mu_{i}$, and make the arrival rate equal to the number of the customers the primary and secondary SPs serve further, i.e., $x_{1}=\lambda_{1}, x_{2}=\lambda_{2}$. Then, we define the congestion function as follows:

$$
\text { Level 1: } g\left(x_{1}\right)=\frac{a_{1} x_{1}}{1-b_{1} x_{1}}
$$

Level 2: $g s\left(x_{1}, x_{2}\right)=\frac{a_{1} x_{1}+a_{2} x_{2}}{\left(1-b_{1} x_{1}\right)\left(1-b_{1} x_{1}-b_{2} x_{2}\right)}$.

For most of our analysis, we also assume that $\mathrm{a}_{1}=\mathrm{a}_{2}$ and $\mathrm{b}_{1}=\mathrm{b}_{2}$, then we have

$$
\begin{aligned}
& g s\left(x_{1}, x_{2}\right)=\frac{a_{1}\left(x_{1}+x_{2}\right)}{\left(1-b_{1} x_{1}\right)\left[1-b_{1}\left(x_{1}-x_{2}\right)\right]} \\
& \quad=g\left(x_{1}+x_{2}\right) \frac{1}{\left(1-b_{1} x_{1}\right)},
\end{aligned}
$$

i.e., the congestion that the secondary users see is caused by the same congestion function $g$ the secondary users see, but represents with total traffic $\mathrm{x}_{1}+\mathrm{x}_{2}$, and increases with the multiplicative term $1 /\left(1-\mathrm{b}_{1} \mathrm{x}_{1}\right)$, which depends on the flow of the primary SP.

Note that $\mathrm{a}_{1}$ and $\mathrm{b}_{1}$ are proportional to the first and second time points of the service and $Y_{1}$, so $2 a_{1}=b_{1}^{2}+\sigma_{Y}^{2}$, where $\sigma_{Y}^{2}$ is the variance of the service time, so it's going to be $a_{1} \geq b_{1}^{2} / 2$, equality with $\sigma_{\mathrm{Y}}^{2}=0$.

\subsection{Equilibrium}

Since the requirements and congestion functions were given in the previous section, we defined a pure strategy of Nash equilibrium for the overall pricing game as a set of prices $\left(\mathrm{p}, \mathrm{P}^{\mathrm{S}}\right)$ and requirements $\left(\mathrm{x}_{1}, \mathrm{X}\right)$, which satisfies the Wardrop equilibrium conditions and additional conditions as mentioned above-no SP can increase its profit by unilaterally changing its price.

\subsection{Monopoly}

Without spectrum sharing, the primary SP acts as a monopolist. Under the premise of market demand, it announces the price maximizes its profit.The optimal price is given by solving the following optimization problem

$$
\begin{array}{rl}
\max & \mathrm{px} \\
\mathrm{p}, \mathrm{x} & \mathrm{p}+\mathrm{g}(\mathrm{x}) \leq \mathrm{P}(\mathrm{x}), \\
\text { with } & 0 \leq \mathrm{x} \leq 1 .
\end{array}
$$

Since the result is continuous and the constraint set is compact and nonempty, and there must be a solution to this problem. Here, the first constraint ensures that the number of customers for the service satisfies the second Wardrop equilibrium condition. If $\mathrm{P}(\mathrm{x})$ is continuous with $P(1)=0$, then any selected $P$ satisfies the constraint, equality; if this is not the case, this constraint is still tight at optimal, since if it was not tight, the monopolist could increase the price and gain more revenue. Here we can replace the first constraint with $\mathrm{p}+\mathrm{g}(\mathrm{x})=\mathrm{P}(\mathrm{x})$, and then we can solve for $\mathrm{p}$ with $\mathrm{x}$. As an optimization, this enables us to describe the problem only in terms of $\mathrm{x}(\mathrm{P}(\mathrm{x})-\mathrm{g}(\mathrm{x}))$, which is $0 \leq \mathrm{x} \leq 1$.

\subsection{Unlicensed Spectrum Sharing}

In unlicensed spectrum sharing, we assume that there are multiple secondary SPs in the market. Since each secondary SP provides a service with the same congestion cost $\mathrm{gs}\left(\mathrm{x}_{1}+\mathrm{x}_{2}\right)$, and the provider who claims the lowest price will get the entire market of the secondary users. As stated in the following conclusions (which can be derived from a similar argument in [10]), this makes the claim price of the secondary SP to be zero.

Lemmas 2.1: In any Nash equilibrium, when the unlicensed spectrum is shared and $\mathrm{N} \geq 2$ for the secondary $\mathrm{SP}$, all active secondary SP will charge the customer a zero price, which is $\mathrm{p}_{\mathrm{i}}^{\mathrm{s}=0}$ for all $\mathrm{i}$.

When there are at least two secondary SPs, the lemma shows all active secondary SP's claimed price is zero. If the secondary SPs serve any customers in a equilibrium, the delivery price will be equal to the congestion gs $(\mathrm{x} 1+\mathrm{x} 2)$. It follows the equilibrium conditions given by the Wardrop equilibrium-When the primary SP serves $\mathrm{x}_{1}$ customers, the total number of customers served in the entire market in equilibrium, $\mathrm{x}^{*}$, must be the solution to the following optimal problem

$$
\begin{array}{cl}
\text { max } & \mathrm{x} \\
\text { with } & \mathrm{g}(\mathrm{x}) \frac{1}{1-\mathrm{b}_{1} \mathrm{x}_{1}} \leq \mathrm{P}(\mathrm{x}), \\
& \mathrm{x}_{1} \leq \mathrm{x} \leq 1 .
\end{array}
$$

You can see that there's a solution to this problem if and only if $\mathrm{g}\left(\mathrm{x}_{1}\right) \frac{1}{1-\mathrm{b}_{1} \mathrm{x}_{1}} \leq \mathrm{P}\left(\mathrm{x}_{1}\right)$. In the absence of a solution, there must be no active secondary SPs. If there is a solution, then it can also be unique. In 
particular, if $\mathrm{P}(\mathrm{x})$ is continuous at $\mathrm{x}^{*}$, then at the optimal solution, the first constraint must be tight, that is, the solution is given by solving

$$
\mathrm{g}(\mathrm{x}) \frac{1}{1-\mathrm{b}_{1} \mathrm{x}_{1}}=\mathrm{P}(\mathrm{x}) \text {. }
$$

Assuming $\mathrm{x} 1, \mathrm{~m}$ is the number of service customers for the primary SP when it was a monopolist. And then, the value of $\mathrm{x} 1$ is considered in (2), it can be concluded that if there is no solution in (2), the primary SP is going to server again $\mathrm{x} 1, \mathrm{~m}$ customer with Unlicensed Spectrum Sharing and no acitve secondary SP. Otherwise, if (2) has a solution $\mathrm{x} 1=\mathrm{x} 1, \mathrm{~m}$, there are two possibilities: (I) the delivery price $g\left(x^{*}\right) \frac{1}{1-b_{1} x_{1, m}}$ is equal to the price the monopolist can get, or (II) the delivered price is less than the monopolist price. In the first case, the primary SP can continue to serve $\mathrm{x} 1, \mathrm{~m}$ customers at the monopoly price and any additional customer is provided by the secondary SPs; In the second case, the primary SP can no longer gain the same benefits as the monopolist. In fact, the result is that in any equilibrium $g\left(x^{*}\right) \frac{1}{1-b_{1} x_{1}}$ will be the price ceiling, so the primary SP must either publish lower prices or serve fewer customers. Note also that $\mathrm{x}^{*}$ and the resulting delivered price ceiling depend on the customer volume(x1) served by the primary SP; In other words, when the primary SP serves fewer customers, $\mathrm{x}^{*}$ will not decrease, so the price limit will not increase. This dependency provides a new potential strategic choice for primary SP, because the increase of the customer number can cause greater congestion for secondary SPs, thus improve the delivery price ceiling. As we'll see in the next few sections, when the service rate changes dramatically, the primary SP will make full use of this privilege and may even drive the secondaries out of the market.

We are now starting to study the Nash equilibrium of the overall pricing game for Shared spectrum. In the nature of the assumed inverse requirements, the following theorem shows that there always exists a Nash equilibrium.

Theorem 2.2: There is always a Nash equilibrium for the priority queue model for shared spectrum.

Proof: when the primary SP serves $\mathrm{x}_{1, \mathrm{~m}}$ customers, there is no solution, so the Nash equilibrium exists directly because the primary SP can simply act as a monopolist and no secondary SP enters the market. Otherwise, the primary SP must consider the "price ceiling" imposed by the secondary SP, and so is facing the following problem

$\begin{array}{ll}\max & \mathrm{px}_{1} \\ \text { with } & \mathrm{p}+\mathrm{g}\left(\mathrm{x}_{1}\right)=\mathrm{g}(\mathrm{x}) \frac{1}{1-\mathrm{b}_{1} \mathrm{x}_{1}}, \\ & \mathrm{~g}(\mathrm{x}) \frac{1}{1-\mathrm{b}_{1} \mathrm{x}_{1}} \leq \mathrm{P}(\mathrm{x}), \\ & \mathrm{p} \geq 0, \mathrm{x}_{1} \leq \mathrm{x} \leq 1 .\end{array}$

Similarly, this problem has a continuous objective and a compact constraint set, so there must be a solution. If the primary SP gets a published price of $\mathrm{p}^{*}$ by solving the problem, and all the secondary SPs declare price to be zero, then this must be a Nash equilibrium.

\section{COMPETITION AND WELFARE ANALYSIS}

In this section, we assume that the inverse function of the customer demand is homogeneous, that is, it is in a "box" shape. All the customers in the market are willing to pay up to the level of the same price, and we have normalized it to be 1 , so

$$
\mathrm{P}(\mathrm{x})= \begin{cases}1, & 0 \leq \mathrm{x} \leq 1, \\ 0, & \text { otherwise }\end{cases}
$$

\subsection{No Spectrum Sharing}

When there is no spectrum sharing, we can rewrite the optimization problem of the primary SP in (1) as

$$
\begin{array}{ll}
\max & \left(1-\frac{\mathrm{a}_{1} \mathrm{x}_{1}}{1-\mathrm{b}_{1} \mathrm{x}_{1}}\right) \mathrm{x}, \\
\text { with } & 0 \leq \mathrm{x} \leq 1 .
\end{array}
$$

Here, as discussed in section 2.4, we take the first constraint equal in (1). To solve this problem, we conclude that when there is no spectrum sharing, the primary SP will serve customers. $\mathrm{x}^{*}=\min \left(\frac{1}{\mathrm{~b}_{1}}-\sqrt{\frac{1}{\mathrm{~b}_{1}}-\frac{1}{\mathrm{~b}_{1}\left(\mathrm{a}_{1}+\mathrm{b}_{1}\right)}}, 1\right)$

As $b_{1}$ is the reciprocal of the average service rate, we'll regard $1 / b_{1}$ as available bandwidth for the primary SP. The next lemma describes how the profit of the primary SP varies with bandwidth.

Lemma 3.1: No spectrum sharing, the profit of the primary SP is going to be non-decreasing at bandwidth $1 / \mathrm{b}_{1}$.

The lemma here is to prove that the profit of the monopolist is given by

$$
\pi_{\mathrm{M}}=\mathrm{X} * \times \max \left(\left(1-\frac{\mathrm{a}_{1} \mathrm{x} *}{1-\mathrm{b}_{1} \mathrm{x}}\right),\left(1-\frac{\mathrm{a}_{1}}{1-\mathrm{b}_{1}}\right)\right),
$$

for $a_{1} \geq b_{1}^{2} / 2$ increasing in the $1 / b_{1}$, as mentioned above, it must be true.

In the case of a monopoly with homogeneous demand, it is easy to see that the consumers will not get any welfare, that is, the delivered price will be equal to 1 . Therefore, in this case, the profit of the primary SP is equal to all social welfare.

\subsection{Spectrum Sharing}

With shared spectrum, the primary SP will compete with the secondary SPs.From the preliminary results of the second section, the secondary SP will charge zero for the customers, which means that if any secondary SP is active, the delivery price is their congestion gs $\left(\mathrm{x}_{1}, \mathrm{x}_{2}\right)=\mathrm{g}\left(\mathrm{x}_{1}+\mathrm{x}_{2}\right) \times$ $\frac{1}{\left(1-b_{1} x_{1}\right)}$. And we know that as $x_{1}$ is the value in (4), (2) is unsolved, no secondary SP is active. In the remainder of this section, we begin the discussion of what is not true. In such case, the profit maximization of the primary SP is solved by

$$
\begin{array}{ll}
\max & \mathrm{px}_{1} \\
\text { with } & \frac{\mathrm{a}_{1}(\mathrm{x})}{1-\mathrm{b}_{1}(\mathrm{x})} \frac{1}{1-\mathrm{b}_{1} \mathrm{x}_{1}} \leq 1, \\
& \begin{array}{l}
\mathrm{p}+\frac{\mathrm{a}_{1} \mathrm{x}_{1}}{1-\mathrm{b}_{1} \mathrm{x}_{1}}=\frac{\mathrm{a}_{1}(\mathrm{x})}{1-\mathrm{b}_{1}(\mathrm{x})} \frac{1}{1-\mathrm{b}_{1} \mathrm{x}_{1}} \\
0 \leq \mathrm{x}_{1} \leq \mathrm{x} \leq 1 .
\end{array}
\end{array}
$$

As the inverse demand $\mathrm{P}(\mathrm{x})$ has a "box" shape, it can be conveniently divided into four forms, as shown in Fig.2 - Fig.5. The first region is shown in Fig.2, where bandwidth is limited and not all customers are served. Here, the primary SP serves part of the customer, the secondary users temporarily access to the spectrum, but the delivery price remains at the ceiling price of 1 . In this case, sharing with the secondary SPs will not affect the profit of the primary SP, as shown in Fig.7. With the increase of bandwidth, the primary and secondary SPs will serve more customers until all customers in the market can accept the service, i.e. the second regional form is shown in Fig.3. At this point, the primary SP serve $\mathrm{x}_{1}=\frac{1-\mathrm{a}_{1}-\mathrm{b}_{1}}{\mathrm{~b}_{1}\left(1-\mathrm{b}_{1}\right)}$ customers. And, if the primary SP wants to maintain a delivery price of 1 , it will have to lower its stated price to gain more customers and cause more congestion on the secondary SP. For a certain range of bandwidth, this is the best strategy for the primary SP. As shown in Fig.7, the primary SP now serves more customers than the monopoly. This market expansion also reduces the number of secondary users, as shown in Fig.7, with a range of bandwidth even reduces to zero. In this case, the primary SP is serving the entire market with a non-monopolistic claim price for the threat of a new entrant, as shown in Fig.6. The conditions for serving the entire market based on non-monopoly prices are given by the following theorem.

Theorem 3.2: If and only if

$$
\mathrm{a}_{1} \leq\left(\mathrm{b}_{1}-1\right)^{2},
$$

then, if the primary SP serves the entire market, it must provide a price lower than the monopoly price because of the threat from the secondary SP. 


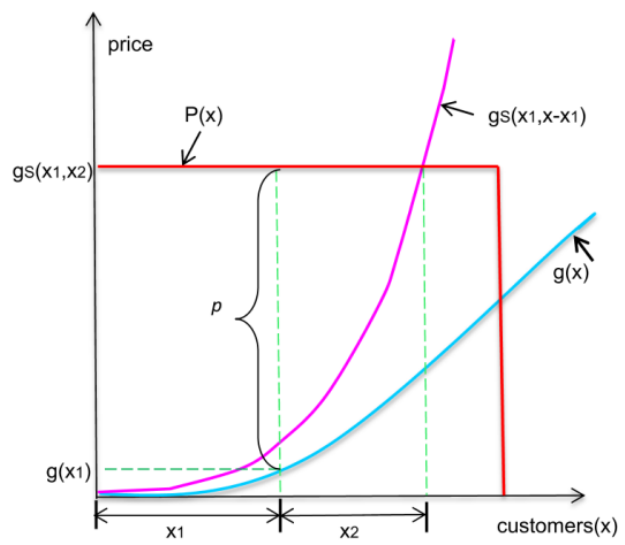

Figure 2: An Example of Pricing Games Using Shared Spectrum under Limited Bandwidth.

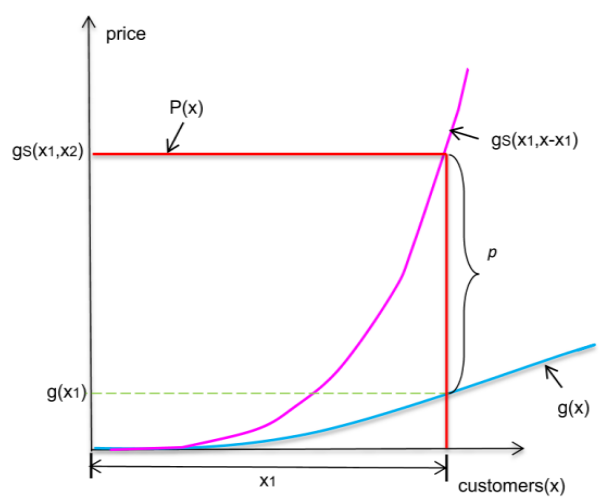

Figure 4: An Example of the Sharing Spectrum Price Game in the Primary SP with the Non-monopoly Price as the Whole Market Service.

Proof: Consider the situation of monopoly firstly. In this case, it can be concluded that when the primary SP announces a price

$$
\mathrm{p}_{1}=1-\frac{\mathrm{a}_{1}}{1-\mathrm{b}_{1}}
$$

it will serve the entire market and lead to a delivery price $p_{1}+g(1)=1$. Moreover, from the analysis of the monopoly situation, we know that when there is sufficient bandwidth, the price will be optimal. In the case of shared spectrum, this price is a balanced, no active secondary SP, and imposes a limit of less than 1 on the delivery price of the primary SP.This is equivalent to the requirement that the delivery price of each secondary

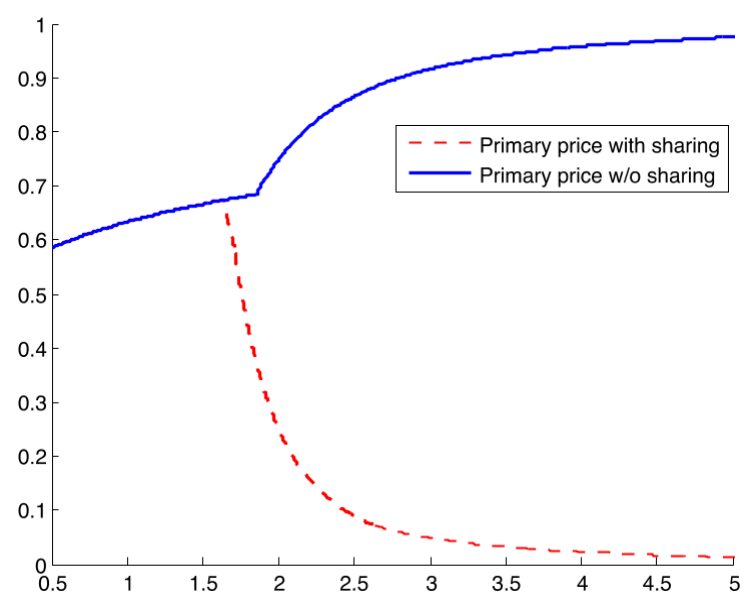

Figure 6: Price of Primary SP When Sharing and Unsharing Spectrum $\left(\sigma_{Y}^{2}=0\right)$.

As the bandwidth gets larger, for the primary SP, getting more customers by lowering price from the secondary SP will eventually become the least optimal. After that, the primary SP will reduce the number of customers, and the number of customers served by the secondary SP will increase.As can be seen from Fig.7, if the bandwidth is sufficient, the primary and

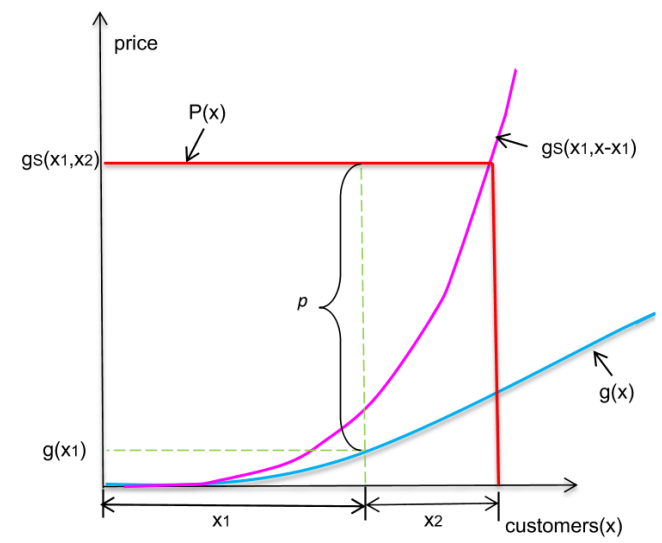

Figure 3: An Example of the Pricing Game Using Shared Spectrum When the Bandwidth Increased but the Delivered Price Stays at the Price Limit.

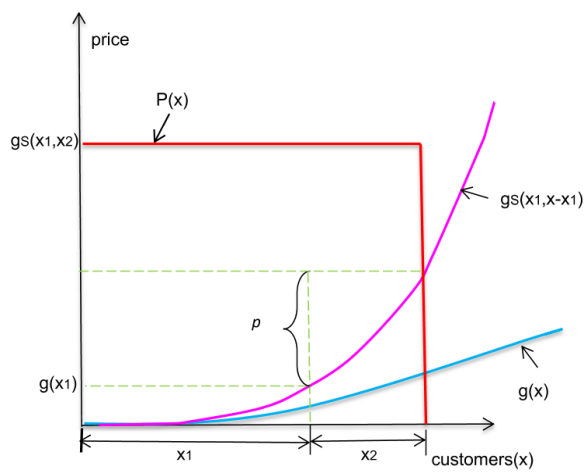

Figure 5: An example of a Shared Spectrum Price Game When the Bandwidth Is Sufficient to Satisfy the Secondary SP Entry and the Delivery Price Is Lower than the Upper Limit.

SP is not less than 1 , and there is no secondary user, i.e.,

$$
\begin{aligned}
1 & \leq \mathrm{gs}(1,0) \\
& =\frac{\mathrm{a}_{1}}{\left(1-\mathrm{b}_{1}\right)^{2}} .
\end{aligned}
$$

In other words, we've shown that if $a_{1} \geq\left(1-b_{1}\right)^{2}$, then the primary SP can serve the entire market, and still monopolizes the price. On the other hand, if this situation is not true, the only way that the primary SP can serve the entire market is that the price is lower than the monopoly price, as shown in Fig.6.

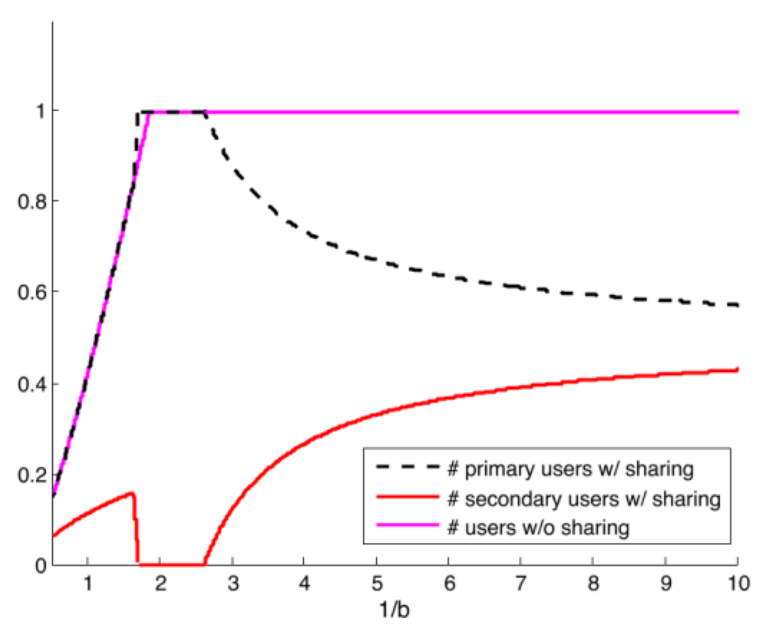

Figure 7: The Number of Primary and Secondary SP Users $\left(\sigma_{Y}^{2}=0\right)$

secondary SPs will segment the market, providing more consumer welfare and social welfare compared with the monopoly situation. It can be concluded that the primary SP will lose its profit, as described in the following theorem. 
Theorem 3.3: When the available bandwidth is large enough, the profit of the primary SP will decrease with the increase of the bandwidth.

In contrast to the monopoly situation, as the bandwidth increases, the profit of the primary SP will gradually decrease to zero. As shown in Fig.4, as the primary SP reduces the number of customers, the congestion of the hared band increases, and its profit decreases slightly.It also reduces social welfare. The results show that for a certain range of bandwidth, social welfare is reduced and less than the social welfare obtained by the monopolist.

\section{CONCLUSION}

In this paper, we assume a scenario-the primary SP shares its spectrum by using priority with multiple secondary SPs, mainly study the primary and secondary SPs' price competition in a common pool of customers.Thus, due to the market expansion strategy of the primary SP, social welfare will be reduced when the shared bandwidth increases.In addition, in the case of spectrum sharing, the primary SP may serve the entire market at a nonmonopoly price due to potential competition from secondary SPs. And, it is possible to explore general requirements functions in future work, including models of investment decisions of the service providers.

\section{ACKNOWLEDGMENTS}

This research is supported by the major scientific research project for the Education Department of JiLin (project number:SREDJCN[2014]343\#).

\section{REFERENCES}

[1] PCAST, Realizing the Full Potential of Government-Held Spectum to Spur Economic Growth. President's Council of Advisors on Science and Technology, 2012.

[2] Federal Communications Commission, Unlicensed operation in the TV broadcast bands, additional spectrum for unlicensed devices below 900 $\mathrm{MHz}$ and in the $3 \mathrm{GHz}$ band. Second memorandum opinion and order, 2010

[3] Federal Communications Commission, Amendment of the commission's rules with regard to commercial operations in the $3550-3650 \mathrm{MHz}$ band, docket no. 12-354, Notice of Proposed Rulemaking, 2012.
[4] Panichpapiboon, S., Peha, J.M. 2003. Providing secondary access in a cellular network, International Conference on Wireless Networks, 591-7.

[5] Saruthirathanaworakun, R., Peha, J.M. 2010. Dynamic PrimarySecondary Spectrum Sharing with Cellular Systems, IEEE Crowncom.

[6] Cabric, D., Mishra, S., Brodersen, R. 2004. Implementation issues in spectrum sensing for cognitive radios, IEEE Asilomar Conference on Signals, systems and computers.

[7] Gurney, D., Buchwald, G., Ecklund, L., Kuffner, S.L., Grosspietsch, J. 2008. Geo-Location Database Techniques for Incumbent Protection in the TV White Space, IEEE DySPAN.

[8] Huang, J., Berry, R., Honig, M. 2006. Auction-based spectrum sharing, ACM Mobile Networks and Applications, 11 (3), 405-418.

[9] Berry, R., Honig, M., Subramanian, V., Nguyen, T., Vohra, R. 2013 Market Structures for Wireless Services with Shared Spectrum, Allerton Conference.

[10] Liu, C., Berry, R. 2014. Competition with Shared Spectrum, IEEE DySPAN.

[11] Liu, C., Berry, R.A. 2014. Competition with Licensed Shared Spectrum, Proceedings of 48th Annual Conference on Information Sciences and Systems.

[12] Nguyen, T., Zhou, H., Berry, R., Honig, M., Vohra, R. 2011. The impact of additional unlicensed spectrum on wireless services competition, IEEE DySPAN, 146-155.

[13] Acemoglu, D., Ozdaglar, A. 2007. Competition and Efficiency in Congested Markets, Mathematics of Operations Research.

[14] Johari, R., Weintraub, G.Y., Roy, B.V. 2010. Investment and Market Structure in Industries with Congestion, Operations Research.

[15] Wardrop, J.G. 1952. Some theoretical aspects of road traffic research. Proceedings, Institute of Civil Engineers, PART II, (1), 325378.

[16] Bertsekas, D., Gallager, R. 1992. Data Networks, Prentice Hall. 